\title{
Article \\ Exploiting IoT and Its Enabled Technologies for Irrigation Needs in Agriculture
}

\author{
Veerachamy Ramachandran ${ }^{1}$, Ramar Ramalakshmi ${ }^{1}$ (D), Balasubramanian Prabhu Kavin ${ }^{2}$ (D), Irshad Hussain ${ }^{3}, *(\mathbb{D}$, \\ Abdulrazak H. Almaliki ${ }^{4}{ }^{\mathbb{D}}$, Abdulrhman A. Almaliki ${ }^{5} \mathbb{D}$, Ashraf Y. Elnaggar ${ }^{6} \mathbb{D}_{\text {and }}$ Enas E. Hussein ${ }^{7, *}$
}

1 Department of Computer Science and Engineering, Kalasalingam Academy of Research and Education, Krishnankoil, Srivilliputhur 626125, Tamil Nadu, India; ramachandran.veer@gmail.com (V.R.); rama@klu.ac.in (R.R.)

2 Sri Ramachandra Faculty of Engineering and Technology, Sri Ramachandra Institute of Higher Education and Research, Porur, Chennai 60011, Tamil Nadu, India; prabhukavin@sret.edu.in

3 Faculty of Electrical and Computer Engineering, University of Engineering and Technology, Peshawar 25000, Pakistan

4 Civil Engineering Department, College of Engineering, Taif University, P.O. Box 11099, Taif 21944, Saudi Arabia; a.almaliki@tu.edu.sa

5 Independent Researcher, Jeddah 12462, Saudi Arabia; a.almaliki1222@gmail.com

6 Department of Food Nutrition Science (Previously Chemistry), College of Science, Taif University, P.O. Box 11099, Taif 21944, Saudi Arabia; aynaggar@tu.edu.sa

7 National Water Research Center, P.O. Box 74, Shubra El-Kheima 13411, Egypt

* Correspondence: ee.irshad@gmail.com (I.H.); enas_elsayed@nwrc.gov.eg (E.E.H.)

check for

updates

Citation: Ramachandran, V.;

Ramalakshmi, R.; Kavin, B.P.

Hussain, I.; Almaliki, A.H.; Almaliki,

A.A.; Elnaggar, A.Y.; Hussein, E.E.

Exploiting IoT and Its Enabled

Technologies for Irrigation Needs in

Agriculture. Water 2022, 14, 719.

https://doi.org/10.3390/w14050719

Academic Editors: Chunhui Li, Zoe Li, Yurui Fan, Celso Augusto Guimarães Santos and Junliang Jin

Received: 17 December 2021

Accepted: 20 February 2022

Published: 24 February 2022

Publisher's Note: MDPI stays neutral with regard to jurisdictional claims in published maps and institutional affiliations.

Copyright: (c) 2022 by the authors. Licensee MDPI, Basel, Switzerland. This article is an open access article distributed under the terms and conditions of the Creative Commons Attribution (CC BY) license (https:// creativecommons.org/licenses/by/ $4.0 /)$.

\begin{abstract}
The increase in population growth and demand is rapidly depleting natural resources. Irrigation plays a vital role in the productivity and growth of agriculture, consuming no less than $75 \%$ of fresh water utilization globally. Irrigation, being the largest consumer of water across the globe, needs refinements in its process, and because it is implemented by individuals (farmers), the use of water for irrigation is not effective. To enhance irrigation management, farmers need to keep track of information such as soil type, climatic conditions, available water resources, soil $\mathrm{pH}$, soil nutrients, and soil moisture to make decisions that resolve or prevent agricultural complexity. Irrigation, a data-driven technology, requires the integration of emerging technologies and modern methodologies to provide solutions to the complex problems faced by agriculture. The paper is an overview of IoT-enabled modern technologies through which irrigation management can be elevated. This paper presents the evolution of irrigation and IoT, factors to be considered for effective irrigation, the need for effective irrigation optimization, and how dynamic irrigation optimization would help reduce water use. The paper also discusses the different IoT architecture and deployment models, sensors, and controllers used in the agriculture field, available cloud platforms for IoT, prominent tools or software used for irrigation scheduling and water need prediction, and machine learning and neural network models for irrigation. Convergence of the tools, technologies and approaches helps in the development of better irrigation management applications. Access to real-time data, such as weather, plant and soil data, must be enhanced for the development of effective irrigation management applications.
\end{abstract}

Keywords: Internet of Things (IoT); agriculture; irrigation; cloud platforms; sensors; controllers; machine learning; neural networks

\section{Introduction}

Water, considered a limited resource, is still an elementary requirement for life on Earth; the upsurge in population growth and climatic changes over several decades has affected water utilization, and water is now in high demand [1,2]. The resources available for agriculture are being depleted at an alarming rate; hence, traditional methods have to be replaced with new methods for the effective utilization of available resources. Soil and water 
are the two main resources for agriculture. As per the Food and Agriculture Organization [FAO] report on Aquastat, India, where more than 55\% of the land is a cultivable area of approximately 183 million ha, irrigation is the major consumer, accounting for more than $80 \%$ of the water resources. The origins and history of irrigation in India have been identified from remains of Indus Valley civilization. Irrigation is a process that has been followed for thousands of years and has undergone several changes and refinements. Supplying the appropriate amount of water to the crop at the appropriate time requires a complexity of irrigation techniques or irrigation management [3,4]. Water use efficiency (WUE) and better yield are the key factors for effective irrigation management application (FAO 2001); this is an important and essential issue to be resolved as the demand to feed the exponentially growing population is high [5-7]. Irrigation optimization is essential to meet the demand for natural resources. Irrigation optimization has been evolving for a long period and has gained attention since the 1970s. Automatic irrigation technologies in precision agriculture based on control theory would result in irrigation optimization [4]. AquaCrop-Open Source is a crop simulation model implemented using MATLAB. Among the water-driven crop models, AquaCrop accounts for a wide spectrum of water stress impacts on transpiration. AquaCrop is a specifically designed simulation model used to simulate the essential factors such as water requirements, growth, biomass production, and harvestable yield of herbaceous crop types [4]. Irrigation optimization includes multiple factors that are not static and change completely with the climate, available resources, crops planted, evapotranspiration, stress coefficient, crop coefficient, electrical conductivity, and many more factors [5]. Irrigation optimization complexity exists due to the heterogeneous problem statements of irrigation. A prescribed static irrigation model will result in a limited scope of improvisation, whereas a dynamic irrigation model would result in high precision. Available technologies, such as IoT, machine learning, and cloud-based decision support systems, reduce the complexity of implementing dynamic irrigation optimization. The adoption rate of modern technologies and data management tools in agriculture is steadily increasing. However, the technologies adopted differ from region to region.

Soil sampling, computers having high-speed Internet access, yield maps, and yield monitoring have the highest rates of adoption among farmers. New technology implementation would result in an increase in yields by $70 \%$.

The application of the right quantity of water at the appropriate time is an important criterion for developing an irrigation management application. The use of machine learning and artificial neural network models will tremendously increase the feasibility of developing a better irrigation management application [6]. This paper reviews the basic technologies, tools, and approaches that can be easily converged to provide solutions to the intricacies in irrigation management. However, this paper does not discuss the economic betterment or government's geographical policies that may also impact on the solution.

\subsection{Evolution of Irrigation}

We examine the evolution of irrigation from the references in four different time periods ranging from 1970 to 2018 (present). The evolution is depicted in Figure 1.

From 1970 to 1985, the emergence of automatic control systems and the scarcity of water for irrigation processes attracted the attention of researchers regarding irrigation optimization [7-10]. Water use information and efficiency were implemented in the late 1970 s as the demand for water started to increase with the exponential rise in the population and depletion of natural resources [11,12]. The scenario triggered the necessity for the optimization of the irrigation technique. Several factors were identified to attain optimization in irrigation, such as the stress day index (SDI), the evapotranspiration crop canopy, and climate conditions. The emergence of the Internet for public use after 1989 has driven Internet-based control systems and enabled data storage on the web. Wireless sensor networks (WSNs) have started to emerge as an easy and powerful technology for environmental monitoring [13]. Sensors and actuators have been developed for various applications of WSNs, including agriculture. Smart applications and methodologies for 
irrigation, soil fertilization, pest control, and disease forecasting have attracted important attention among researchers in the field of precision agriculture [14-24].

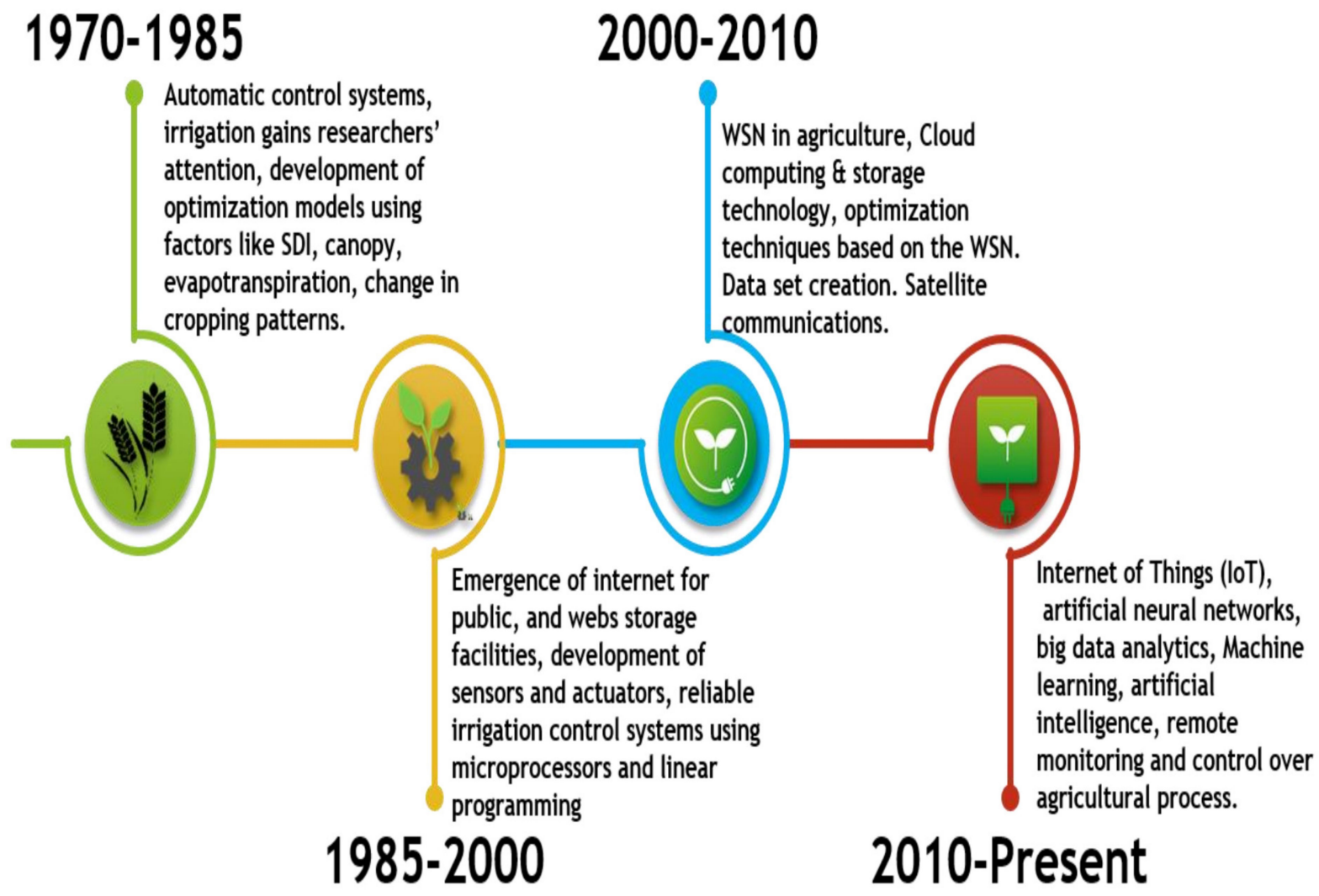

Figure 1. Evolution of irrigation from 1970 to present.

\subsection{Factors to Be Considered for Effective Irrigation}

Several irrigation systems, or characteristics of irrigation systems, exist based on the application or utilization of the water to the surface or the crop. These are normally classified as surface, drip, or sprinkler, and localized and subsurface irrigation. Surface irrigation irrigates by applying water on the surface of the agricultural land. Drip or sprinkler irrigation uses less water for irrigation as it applies the water drop by drop or sprinkles it like artificial rain, whereas localized irrigation applies water to specific places on the surface, and, in subsurface irrigation, water is applied to the crop's root zone [25].

Many factors are dependent on the type of irrigation optimization that is performed [15-17]. Furthermore, all of the factors differ based on the geography, crop, soil type, irrigation methodology, and the amount of rainfall $[18,19]$. Below are some of the vital factors affecting irrigation optimization:
1. Soil moisture.
2. $\mathrm{pH}$ value.
3. Electrical conductivity.
4. Crop growth metrics.
5. Climate data.
6. Crop canopy.
7. Evapotranspiration.

Given the difficulty of establishing successful irrigation, it is prudent to estimate the irrigation need and optimize it through the development of an irrigation optimization approach that takes into account all of the complicated irrigation characteristics. 


\subsection{Irrigation Optimization}

Irrigation optimization is a complex task as it involves the processes of data collection, analysis, and interpretation of acquired data and optimization decisions. Optimization is attained using different factors as the irrigation impact differs based on various factors. Montesano et al. (2018) designed and deployed an automated irrigation system where soilless substrate was taken for growing basil and stated that a wireless sensor network can be used as an effective tool for real-time monitoring and sensing of substrate water status in greenhouse soilless conditions for effective irrigation management of basil [20].

Difallah et al. (2017) developed a linear programming model along with a knapsack decisional form to attain irrigation optimization with weather and soil conditions as vital factors, and the results reduced the utilization of water by $28.5 \%$ [21]. Consideration of other external factors of importance, such as relative humidity, soil nutrients, wind speed, and sunshine duration, would result in better optimization.

An integrated hydrological-irrigation optimization modeling system was implemented for the Central Vietnam rice irrigation scheme [22]. The model comprises a distributed hydrologic model, a simulated inflow for the reservoir, and an irrigation methodology that optimizes the irrigation of rice. Continuous flooding is replaced with alternate wetting and drying (AWD) throughout the summer-autumn season, and the reservoir capacity and reservoir release are considered to be important factors.

Zhang et al. [23] irrigated tomatoes at different crop evapotranspiration (ETc) percentages, such as $40 \%, 50 \%, 60 \%, 80 \%$, and $100 \%$, finding that the highest yield was obtained with $80 \%$ ETc, and recommended $80 \%$ ETc as an optimal irrigation standard for the Hetao Irrigation District comprising sandy soil.

A smart drip irrigation system combining technologies such as the cloud, data mining, and Android [24] was developed by Ghosh et al., and they achieved remote control over the drip irrigation. Humidity, temperature, light, and moisture are considered as important factors in irrigation control. Factors such as temperature and humidity in the air, soil moisture, wind speed, and solar radiation can be considered universal variables in agricultural applications.

Before optimizing the irrigation, the right irrigation technique must be chosen based on the farm and other factors [21]. Several irrigation techniques are available among these, of which flood, drip, and sprinkler irrigation are the most applied techniques.

Other irrigation methods have also been followed as per the geographic demands and research process.

\subsection{Remote Monitoring and Control of Irrigation for Optimized Irrigation}

Irrigation monitoring is critical for optimization; thus, manual monitoring should be phased out in favor of automated or remote monitoring. Numerous irrigation systems are used across the world, and Table 1 summarizes the numerous strategies used in the reference articles. In 2018, Karimi et al. [25,26] developed a web-based monitoring system for vineyards and grape drying, and the results proved it was a complete monitoring system that provided efficient monitoring.

Table 1. Various irrigation techniques.

\begin{tabular}{cc}
\hline Various Irrigation Techniques & References \\
\hline Flood irrigation & {$[17,22,25,27,28]$} \\
\hline Alternate wetting and drying (AWD) & {$[22]$} \\
\hline Sprinkler irrigation & {$[21,27,29,30]$} \\
\hline Drip irrigation & {$[23,24,31-33]$} \\
\hline Micro irrigation & {$[14,34]$} \\
\hline
\end{tabular}


Table 1. Cont.

\begin{tabular}{cc}
\hline Various Irrigation Techniques & References \\
\hline Low-pressure pipe irrigation & {$[21,33,35]$} \\
\hline Channel lining & {$[36,37]$} \\
\hline Furrow irrigation & {$[28,35]$} \\
\hline Pivot irrigation & {$[32]$} \\
\hline
\end{tabular}

Das et al. considered four key data fields, namely, the morphology of the plant, canopy, leaf area index, and fruit counts, using sensor suites containing a laser range scanner, multispectral cameras, a thermal imaging camera, and navigational sensors. Using the sensor suites, they were able to monitor the agriculture process effectively [26].

Gosh et al. developed a remote monitoring and control system where the field data were collected using preconfigured sensors and passed on to the controller, which passes the information to a computer on the farm, from which the data are transferred to the cloud [24]. The emergence of critically designed IoT devices and controllers enables the field data to be directly stored in the cloud without a computer to interface the field and cloud [38]. Precision agriculture has to be complemented with emerging technologies, such as the Internet of Things (IoT), and has enabled technologies to improve the quality of farming [39]. Monitoring the field and fetching data from the farm helps in monitoring and analyzing other processes in precision agriculture [40], such as the soil nutrient depletion rate, crop canopy, and other parameters. Researchers used cloud services to save the data for further analysis. An automated cloud-based dynamic decision support system for acquiring data from different sources was developed by Tan in 2016 and was tested successfully. The system was able to provide decisions that were application specific, and the field devices could be controlled from the cloud [41]. These cloud-assisted platforms increase the scope of analytics and decision support systems in precision agriculture [27].

Imaging platforms have also been used for remote monitoring [42], as several parameters, such as the canopy, detection of leaf width, and infection in plants, can be performed using image processing algorithms and other approaches in combination with image processing.

Irrigation optimization, remote monitoring, and remote control complement each other to enable precision agriculture. The process cycle is depicted in Figure 2.

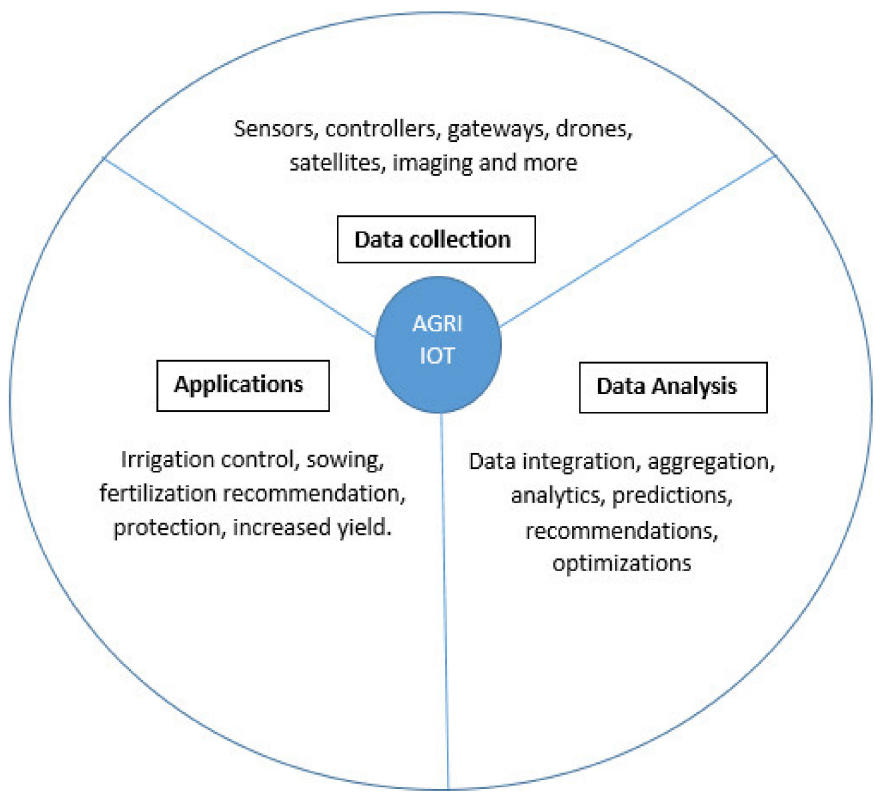

Figure 2. Components of precision agriculture. 


\section{Architecture or Deployment Models for IoT in Agriculture Irrigation Management}

A remote monitoring system based on the Internet of Things employs a variety of methodologies for a variety of applications, and hence the design and deployment patterns are diverse. There is no one-size-fits-all approach to IoT architecture. Consolidation of the Internet of Things architecture is based on a three- or four-layer architecture.

\section{Three-Layer and Four-Layer Architectures}

The common architecture is the three-layer architecture represented in Figure 3, comprising the physical, network and application layers [43].
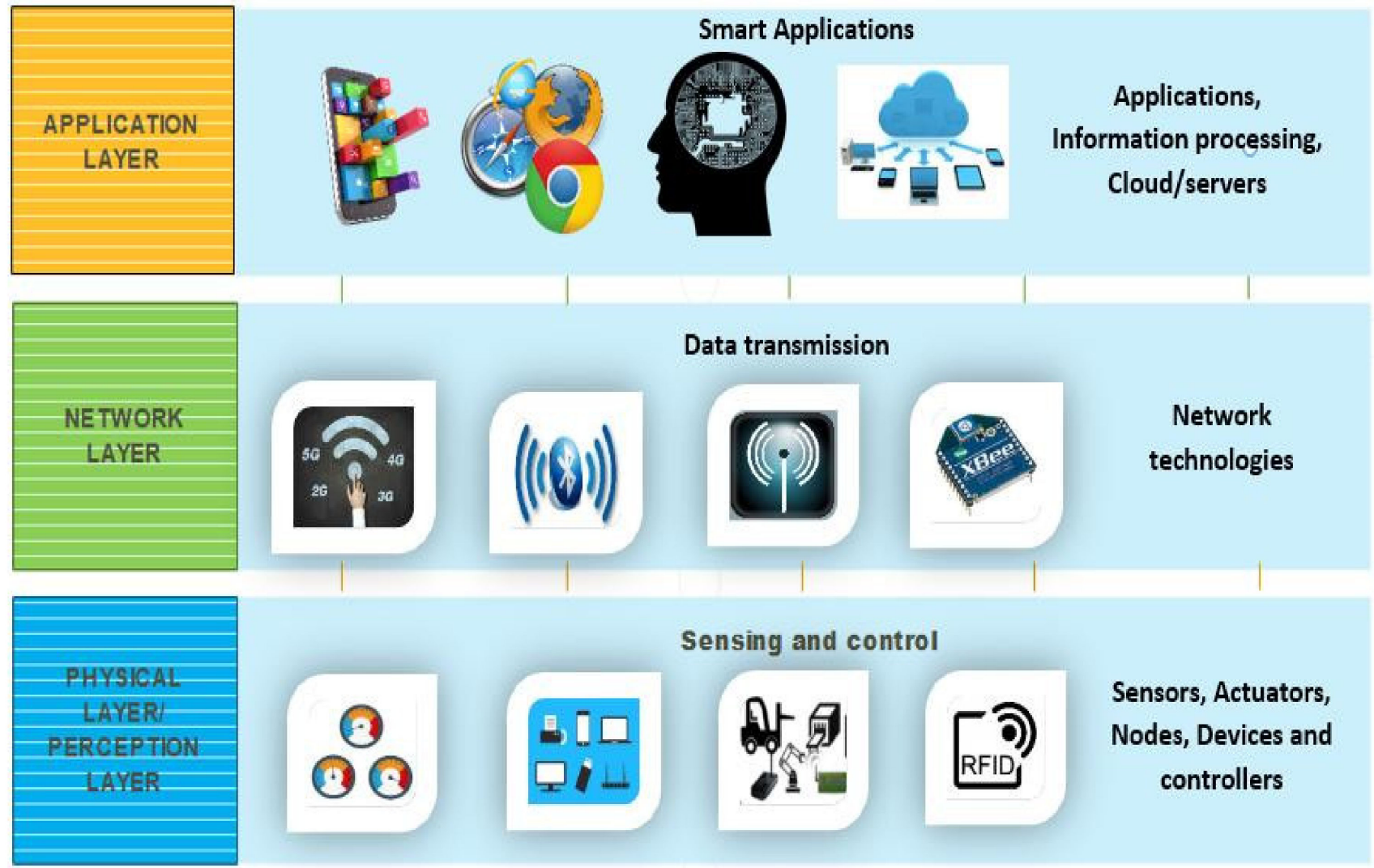

Data transmission
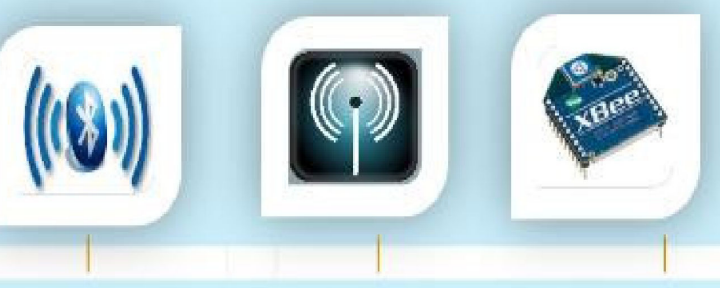

\section{Network technologies}
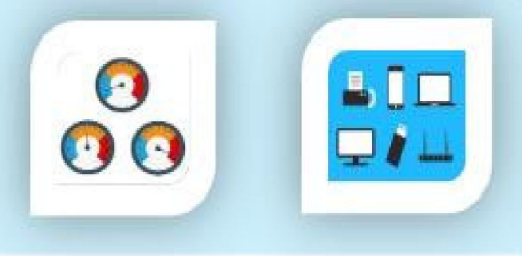

Sensing and control
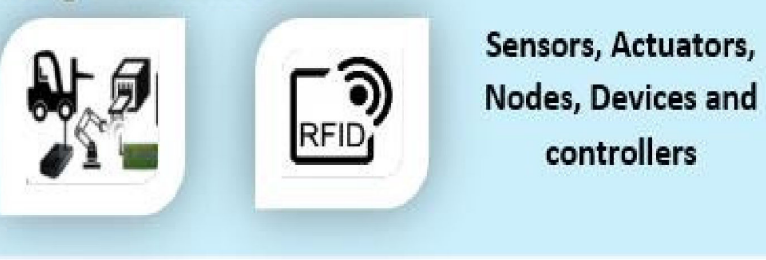

Figure 3. Generic three-layer architecture.

i. The sensor and actuator layer (physical layer) has the sensors and actuators connected to it, allowing sensing to gather information from the environment and to control the actuators

ii. The network layer (data management layer) connects other devices, servers, and things in the IoT application. This layer is sometimes called the communication layer, as it merges some of the functions, such as data aggregation and preprocessing.

iii. The application layer delivers application-driven services or functions to the end users. The functions and process differ based on the application in which it is used, such as smart homes, smart cities, and smart agriculture.

In the four-layer architecture depicted in Figure 4, the service layer is added to the three-layer architecture, and the service layer classifies the data for the application layer. The data are classified based on applications such as visualization, security, storage, communication services, and analytics. The service layer is accountable for the creation and management of services needed for applications. It acts as a middleware for the application and network layer, and is responsible for maintaining the services registry for discovery of 
services, API (application programming interface), and composition of services. Reliability management is also taken care of by the service layer.

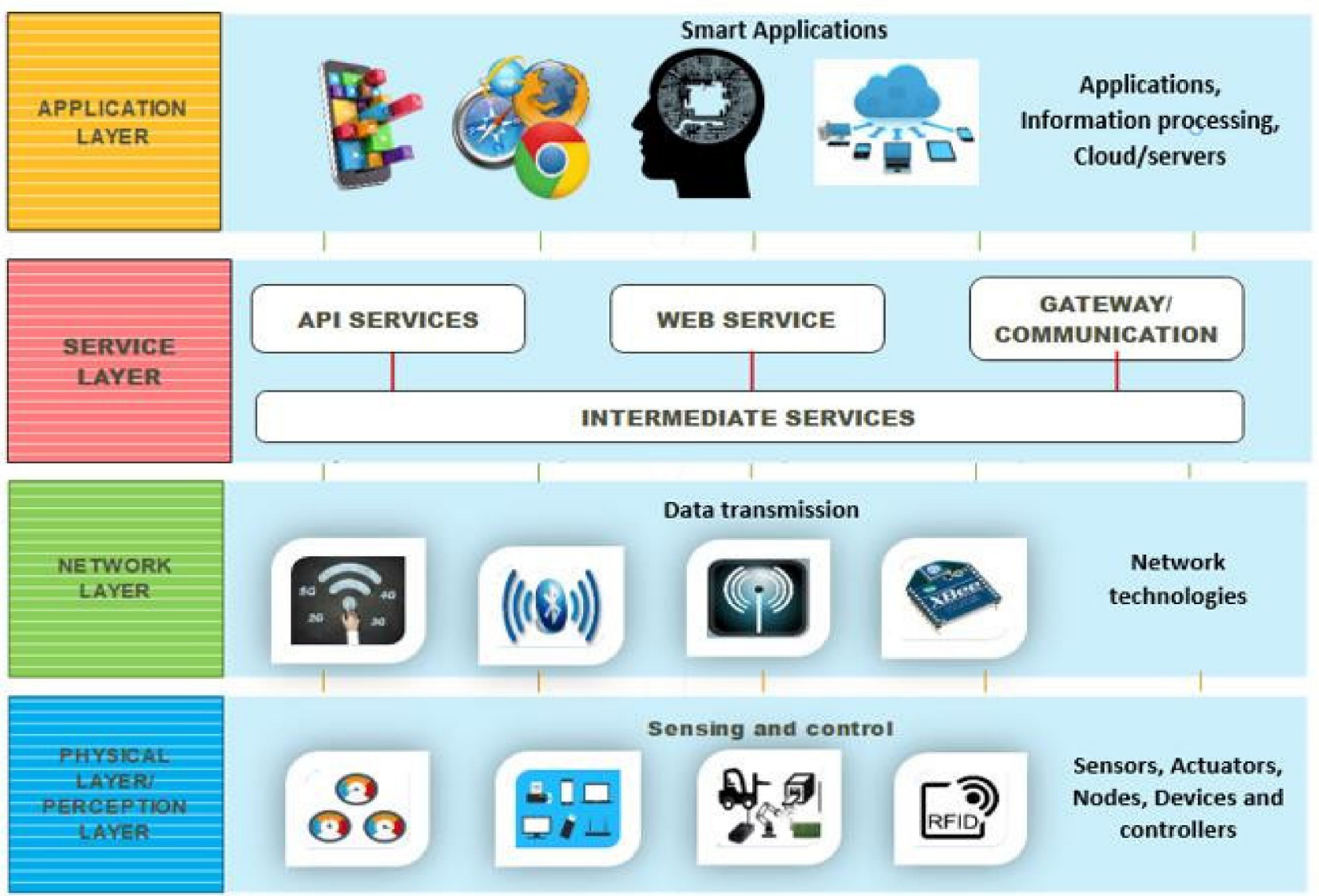

Figure 4. Four-layer architecture.

\section{Commonly Used Cloud Platforms in IoT}

As per the National Institute of Standards and Technology (NIST), "cloud computing is a model for enabling ubiquitous, convenient, on-demand network access to a shared pool of configurable computing resources (e.g., networks, servers, storage, applications, and services) that can be rapidly provisioned and released with minimal management effort or service provider interaction" [43-50]. The integration of the cloud platform is an important factor for developing an effective application in the IoT. Most IoT applications are developed to complement data collection in an analytics application. The cloud also helps attain scalability and flexibility, and, with clouds, features such as visualization and data analysis are easily carried out, reducing the time and cost required of applications. Multiple cloud platforms are compared and contrasted in Table 2. 
Table 2. Cloud platforms of IoT comparison.

\begin{tabular}{|c|c|c|c|c|c|c|c|c|c|c|}
\hline $\begin{array}{l}\text { Applications/Cloud } \\
\text { Service Providers }\end{array}$ & Open Source & $\begin{array}{c}\text { Device } \\
\text { Management }\end{array}$ & $\begin{array}{l}\text { Security } \\
\text { Built in }\end{array}$ & $\begin{array}{c}\text { Machine } \\
\text { Learning Tools }\end{array}$ & $\begin{array}{c}\text { Data } \\
\text { Management }\end{array}$ & Analytics & Virtualization & $\begin{array}{c}\text { Mobile } \\
\text { Application } \\
\text { Support }\end{array}$ & Visualization & $\begin{array}{l}\text { Developer } \\
\text { Tools }\end{array}$ \\
\hline AWS IOT & no & $\checkmark$ & $\checkmark$ & $r$ & $\checkmark$ & no & $\checkmark$ & $\checkmark$ & $\checkmark$ & $\checkmark$ \\
\hline Artik Cloud & no & 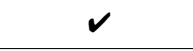 & $\checkmark$ & no & no & $\checkmark$ & no & no & $\checkmark$ & $\checkmark$ \\
\hline $\begin{array}{l}\text { Autodesk Fusion } \\
\text { Connect }\end{array}$ & no & $v$ & $\checkmark$ & no & $\checkmark$ & $\checkmark$ & $v$ & no & $\checkmark$ & $\checkmark$ \\
\hline GE Predix & no & $v$ & $v$ & $\checkmark$ & $\checkmark$ & $\checkmark$ & $\checkmark$ & $v$ & $v$ & no \\
\hline Google Cloud IoT & no & $\checkmark$ & $v$ & no & $\checkmark$ & $\checkmark$ & no & $\checkmark$ & $\checkmark$ & no \\
\hline $\begin{array}{l}\text { Microsoft Azure } \\
\text { IoT Suite }\end{array}$ & no & no & $\boldsymbol{v}$ & $\checkmark$ & $\checkmark$ & $\checkmark$ & no & $\boldsymbol{v}$ & $\checkmark$ & $\checkmark$ \\
\hline IBM Watson IoT & no & $\checkmark$ & $\checkmark$ & $\checkmark$ & $\checkmark$ & $\checkmark$ & no & no & $\checkmark$ & $\checkmark$ \\
\hline Salesforce IoT Cloud & no & $\checkmark$ & no & no & $\checkmark$ & $\checkmark$ & no & no & $\checkmark$ & no \\
\hline Kaa Platform & $\checkmark$ & no & no & no & $\checkmark$ & $\checkmark$ & no & no & $\checkmark$ & $\checkmark$ \\
\hline Macchina Platform & $\checkmark$ & $\checkmark$ & no & no & $\checkmark$ & no & no & $\checkmark$ & $v$ & $\checkmark$ \\
\hline $\begin{array}{l}\text { Microsoft Lab } \\
\text { of Things }\end{array}$ & no & $\checkmark$ & $\checkmark$ & $\boldsymbol{v}$ & $\checkmark$ & no & no & no & $\checkmark$ & $\checkmark$ \\
\hline Oracle IoT & no & $\checkmark$ & $\checkmark$ & no & $\checkmark$ & $\checkmark$ & $\checkmark$ & no & $\checkmark$ & no \\
\hline SiteWhere Platform & $\checkmark$ & $\checkmark$ & no & no & no & no & no & no & no & $\checkmark$ \\
\hline Carriots Platform & $v$ & $v$ & no & no & no & no & no & no & $v$ & $\checkmark$ \\
\hline Temboo Platform & no & no & no & no & $\checkmark$ & $\checkmark$ & no & no & $\checkmark$ & $\checkmark$ \\
\hline Thethings.io & $\checkmark$ & $\checkmark$ & no & no & no & no & no & $\checkmark$ & $\checkmark$ & $\checkmark$ \\
\hline Thing speak & $\checkmark$ & $\checkmark$ & no & no & $\checkmark$ & $\checkmark$ & no & no & $\checkmark$ & $\checkmark$ \\
\hline Thing Worx & no & $\checkmark$ & no & no & $\checkmark$ & $\checkmark$ & no & no & $\checkmark$ & $\checkmark$ \\
\hline Ubidots Platform & $\checkmark$ & $\checkmark$ & no & no & $\checkmark$ & $\checkmark$ & no & no & $\checkmark$ & 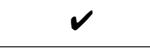 \\
\hline Xively & no & $\checkmark$ & $\checkmark$ & no & $\checkmark$ & $\checkmark$ & no & no & $\checkmark$ & no \\
\hline
\end{tabular}




\section{Commonly Used Sensors and Controllers in Agriculture}

\subsection{Sensors in Agriculture}

The sensor collects data from the field and aggregates it for processing in an IoT application. The actuators in the application are mostly activated by detected data. Sensor data is gathered and used in analytics and visualization-based applications. The following are some of the more obvious sensors mentioned in the cited article(s):

1. Soil moisture sensor.

2. Weather station.

3. $\mathrm{CO}_{2}$ sensor.

4. DHT11 digital.

5. TGS 813 sensor for $\mathrm{SO}_{2}$ gas.

6. PIR motion sensor.

7. Soil $\mathrm{pH}$ sensor.

\subsection{Hardware Platforms in the IoT}

Hardware platforms connected with sensors and actuators are the heart of the IoT. In the case of IoT hardware, it is designed or amended depending on the application in which it is used. The hardware used in the IoT consists of two types of ARM controllers, as compared in Table 3, and Single Board Computers, as contrasted in Table 4. The tables present the available and commonly used hardware platforms, with parameters of supply voltage, processor, processor speed, system flash, system memory, IDE, GPIO, I/O, connectivity, and network interfaces.

The data collected from the farm using the IoT devices and cloud platform enable the analysis of data through which several complexities can be visualized and resolved, such as estimation of evapotranspiration and irrigation for the upcoming days, prediction of yield, and scheduling of irrigation based on the acquired value. To perform the analysis, machine learning and neural networks are deployed. The following section discusses some of the many studies for irrigation management that use machine learning models or neural networks for effective irrigation. 
Table 3. Comparison of ARM-based controllers.

\begin{tabular}{|c|c|c|c|c|c|c|c|}
\hline $\begin{array}{l}\text { Parameters/ } \\
\text { Microcontroller } \\
\text { Based Boards }\end{array}$ & Arduino Uno & Arduino Yun & Particle Electron & $\begin{array}{l}\text { Espressif Systems } \\
\text { ESP8266-01 }\end{array}$ & Node MCU. & $\begin{array}{l}\text { ARM mbed NX- } \\
\text { PLPC1768Processor }\end{array}$ & Electric Imp 003 \\
\hline Supply Voltage & $5 \mathrm{~V}$ & $5 \mathrm{~V} / 3.3 \mathrm{~V}$ & $3.3 \mathrm{~V}$ & $3.3 \mathrm{~V}$ & $3.3 \mathrm{~V}$ & $5 \mathrm{~V}$ & $5 \mathrm{~V}$ \\
\hline Processor & ATMega328PU & $\begin{array}{l}\text { ATmega32u4, and } \\
\text { Atheros } \\
\text { AR9331 }\end{array}$ & 32-bit STM32F205 & 32-bit Tensilica L106 & 32-bit Xtensa L106 & $\begin{array}{l}\text { ARM } \\
\text { Cortex } \\
\text { M3 }\end{array}$ & $\begin{array}{l}\text { ARM } \\
\text { Cortex } \\
\text { M4F }\end{array}$ \\
\hline $\begin{array}{l}\text { Processor speed } \\
\text { (MHZ) }\end{array}$ & 16 & 16 & 120 & 80 & 80 & 300 & 96 \\
\hline System Flash & $32 \mathrm{~KB}$ & $16 \mathrm{MB}$ & 128 KB RAM & - & $128 \mathrm{~KB}$ & $512 \mathrm{~KB}$ & $4 \mathrm{MB}$ \\
\hline System Memory & $16 \mathrm{MB}$ & $64 \mathrm{MB}$ & $1 \mathrm{MB}$ & $1 \mathrm{MB}$ & $16 \mathrm{MB}$ & $120 \mathrm{~KB}$ & $32 \mathrm{~KB}$ \\
\hline IDE & Arduino & Arduino & Arduino & $\begin{array}{l}\text { Online Compiler, } \\
\text { Arduino }\end{array}$ & Arduino & $\begin{array}{l}\mathrm{C} / \mathrm{C}++ \\
\text { SDK, } \\
\text { Online } \\
\text { Compiler }\end{array}$ & $\begin{array}{l}\text { Electric } \\
\text { Imp }\end{array}$ \\
\hline GPIO & $\begin{array}{l}6 \text { Analog in } \\
14 \text { Digital—6 PWM }\end{array}$ & $\begin{array}{l}12 \text { Analog in } \\
20 \text { Digital-7 PWM }\end{array}$ & $\begin{array}{l}12 \text { Analog In,2 } \\
\text { Analog out, } 30 \\
\text { Digital-15 PWM }\end{array}$ & $\begin{array}{l}2 \text { Digital } \\
1 \text { Analog }\end{array}$ & $\begin{array}{l}1 \text { Analog in } \\
16 \text { Digital }\end{array}$ & $\begin{array}{l}6 \text { Analog in } \\
20 \text { Digital—6 PWM }\end{array}$ & $\begin{array}{l}5 \text { Analog } \\
6 \text { Digital }\end{array}$ \\
\hline I/O Connectivity & $\begin{array}{l}\text { SPI, I2C, } \\
\text { UART, } \\
\text { GPIO }\end{array}$ & $\begin{array}{l}\text { SPI, I2C, } \\
\text { UART, } \\
\text { GPIO }\end{array}$ & $\begin{array}{l}\text { SPI, I2C, } \\
\text { UART, } \\
\text { GPIO }\end{array}$ & $\begin{array}{l}\text { SPI, I2C, } \\
\text { UART, } \\
\text { GPIO }\end{array}$ & $\begin{array}{l}\text { SPI, I2C, } \\
\text { UART, } \\
\text { GPIO }\end{array}$ & $\begin{array}{l}\text { SPI, I2C, } \\
\text { UART, CAN } \\
\text { GPIO }\end{array}$ & $\begin{array}{l}\text { SPI, I2C, } \\
\text { UART, } \\
\text { GPIO }\end{array}$ \\
\hline Network Interfaces & $\begin{array}{l}\text { No, can be added as } \\
\text { ad-on. }\end{array}$ & $\begin{array}{l}\text { No, can be added as } \\
\text { ad-on. }\end{array}$ & $\begin{array}{l}\text { Integrated GPRS } \\
\text { modem }(2 \mathrm{G} / 3 \mathrm{G})\end{array}$ & Wi-Fi & Wi-Fi & $\begin{array}{l}\text { No, can be added as } \\
\text { ad-on. }\end{array}$ & Wi-Fi \\
\hline
\end{tabular}


Table 4. Single Board Computer-based hardware for IOT.

\begin{tabular}{|c|c|c|c|c|c|}
\hline $\begin{array}{l}\text { Parameters/Single } \\
\text { Board Computers }\end{array}$ & Raspberry Pi 3 Model B & $\begin{array}{l}\text { Intel } \\
\text { Galileo Gen2 }\end{array}$ & $\begin{array}{l}\text { Intel } \\
\text { Edison }\end{array}$ & $\begin{array}{l}\text { Beagle } \\
\text { Bone Black }\end{array}$ & $\begin{array}{l}\text { Qualcomm } \\
\text { DragonBoard 410c }\end{array}$ \\
\hline Supply voltage & $3.3 \mathrm{~V}$ & $5 \mathrm{~V}$ & $3.3 \mathrm{~V}$ & $3.3 \mathrm{~V}$ & $1.8 \mathrm{~V}$ \\
\hline Processor & ARM CORTEX A53 & $\begin{array}{l}\text { IntelQuarkTM } \\
\text { SoC X1000 }\end{array}$ & $\begin{array}{l}\text { IntelQuarkTM } \\
\text { SoCX1000 }\end{array}$ & SitaraAM3358BZCZ100 & ARM CORTEX A53 \\
\hline Processor speed(HZ) & $1.2 \mathrm{GHZ}$ & $400 \mathrm{MHZ}$ & $500 \mathrm{MHz}$ & $1 \mathrm{GHZ}$ & $1.2 \mathrm{GHZ}$ \\
\hline RAM & $1 \mathrm{~GB}$ & $256 \mathrm{MB}$ & $1 \mathrm{~GB}$ & $512 \mathrm{MB}$ & $1 \mathrm{~GB}$ \\
\hline System Memory & Supports 8/16 GB & $8 \mathrm{MB}$ & $4 \mathrm{~GB}$ & $4 \mathrm{~GB}$ & $8 \mathrm{~GB}$ \\
\hline IDE & $\begin{array}{l}\text { NOOBS, Debian, } \\
\text { Android, } \\
\text { Ubuntu, } \\
\text { Cloud9 IDE }\end{array}$ & ArduinoIDE & $\begin{array}{l}\text { ArduinoIDE, Eclipse, } \\
\text { Intel XDK }\end{array}$ & $\begin{array}{l}\text { Debian, } \\
\text { Android, } \\
\text { Ubuntu, } \\
\text { Cloud9 IDE }\end{array}$ & $\begin{array}{l}\text { Debian, } \\
\text { Android, } \\
\text { Ubuntu, } \\
\text { Cloud9 IDE }\end{array}$ \\
\hline GPIO & $\begin{array}{l}40 \text { I/O pins, including } 29 \\
\text { Digital }\end{array}$ & 14 Digital, 6-Analog & 14 Digital, 6-Analog & $\begin{array}{l}65 \text { Digital-8 PWM } \\
7 \text { Analog in }\end{array}$ & 12 Digital \\
\hline I/O Connectivity & $\begin{array}{l}\text { SPI, DSI, } \\
\text { UART, SDIO, } \\
\text { CSI, GPIO }\end{array}$ & $\begin{array}{l}\text { SPI, I2C, } \\
\text { UART, } \\
\text { GPIO }\end{array}$ & $\begin{array}{l}\text { SPI, I2C, } \\
\text { UART, } \\
\text { I2S, GPIO }\end{array}$ & $\begin{array}{l}\text { SPI, UART, I2C, } \\
\text { McASP, GPIO }\end{array}$ & $\begin{array}{l}\text { SPI, UART, I2C, } \\
\text { McASP, GPIO }\end{array}$ \\
\hline Network Interfaces & Wifi, Ethernet, Bluetooth & Ethernet & $\mathrm{Wi}-\mathrm{Fi}$ & $\begin{array}{l}\text { Ethernet, USB ports allow } \\
\text { external wifi/Bluetooth } \\
\text { adaptors }\end{array}$ & Wifi, Bluetooth, GPS \\
\hline
\end{tabular}




\section{Artificial Neural Networks and Machine Learning for Irrigation}

Machine learning is the process of building a mathematical model that uses the available data to learn decision making using the patterns and features of the data. The sample or the training data are the base of the machine learning models, which generate decisions or predictions without a traditional program that explicitly instructs a computer to do so [44]. Neural networks embed the process of imitating the operations of the human brain to perform tasks through a non-explicit programming structure, where sample data or training data are used to fetch insights from the available data resources. Machine learning is considered the subset of neural networks [50-61]. With the enormous amount of data, machine learning or artificial neural networks would help in identifying the pattern hidden inside the data. Machine learning and neural networks for the betterment of irrigation management use several factors as parameters; among the parameters, reference evapotranspiration (ET) is the most widely used.

Cordeiro et al. predicted soil moisture for irrigation management as soil moisture data was not properly retrieved from the farm due to sensor failure. A fog-enabled smart system for irrigation was deployed using neural networks [62-66].

Optimal water application or control was achieved using a convolution neural network (CNN) for a sugarcane crop. The proposed CNN provided better water control with high accuracy compared to other models [67-70]. Although several factors help in attaining irrigation optimization, evapotranspiration is the most preferred as it is derived using other key parameters.

Evapotranspiration is a significant element, not only in irrigation management, but also in many other applications. Evapotranspiration (ET) estimation depends on several models, and the Penman-Monteith model is a highly followed standard across the globe among many researchers for the estimation of ET [46].

Mohammad rezapour et al. in 2019 estimated ET by comparing and contrasting three models, namely, the support vector machine (SVM), adaptive neuro fuzzy inference system (ANFIS), and gene expression programming (GEP). All three models estimated the potential evapotranspiration for semi-arid land [47]. The simulation of ET was performed for the data ranging from 1970-2010, with inputs of five different combinations in southeastern Iran. Among the three models, ANFIS is a neural network model, SVM is a machine learning model, and GEP is an evolutionary computing technique. The SVM-based model performed better than the other two models, with sunshine hours, humidity, relative humidity, air temperature average, and wind speed as the input parameters for the model [70-74].

Feng et al. estimated the ET for the collected data from two stations in China for the years 2009-2014 using the temperature-based random forest model (RFM) and generalized regression neural network (GRNN) model [48]. From the results, it is clear that both models can be used for the estimation of ET on a daily basis, and both the RFM and GRNN perform well in terms of daily estimation. However, the slight performance improvement of the RFM makes it a preferred choice compared with the GRNN model.

Yamac and Todorovic estimated the daily crop evapotranspiration (ETc) for potato using K-Nearest Neighbor (KNN), Adaptive Boosting (AdaBoost) and ANN (artificial neural network) models. The three models were tested for four different input parameter setups. The estimation of the models was compared with the ETc estimated using the standard Penman-Monteith methodology. The meteorological data collected from a test plot in southern Italy for the durations of 2009 and 2010 were used for comparison. The results show that the KNN model performed well for the scenario with limited input data. The ANN performed well with a complete set of input data [49].

The estimation of ET for the data collected from two meteorological stations in Turkey was examined by Sanikhani et al. in 2019 with six different AI models. The models used limited climatic data for estimation. The examined models were multilayer perceptron, radial basis neural network (RBNN), GEP, ANFIS with grid partition (ANFIS-GP), ANFIS with subtractive clustering (ANFIS-SC), and GRNN. The models were verified with the Hargreaves-Samani (HS) and Calibrated Hargreaves-Samani (CHS) approaches of estima- 
tion. The results show that GRNN and the GEP performed well at a station named Antalya, and at another station named Isparta; the ANFIS-SC and the RBNN models performed well in comparison with other models [50]. All six models, except the multilayer perceptron, performed well compared to CHS and the HS empirical approaches.

ET-based irrigation management models are reliable models, but they require many input variables that are not easily available and are not easily collected from farms using IoT devices. Research to extract the data required for ET estimation is in high demand [46]. Along with the reference ET method, many other parameters, such as canopy cover, rainfall data, water stress index, and normalized difference vegetation index (NDVI), are also used for irrigation management.

Machine learning and artificial neural networks not only encourage researchers to make irrigation recommendations but also encourage the use of many other factors, such as crop suitability, yield prediction, plant disease classification, and profitable plantations [56,57]. Many of the previous research works have been enhanced with machine learning-based models for better classification and artificial intelligence-based predictions for more accuracy and efficiency [58,59].

\section{Tools or Software Available for Irrigation Management}

Because irrigation management has been the subject of research for a period of several decades, multiple tools have been developed for irrigation scheduling and the estimation of irrigation requirements, which are considered to be a part of irrigation management. This paper discusses some of the notable tools or software for irrigation management.

\subsection{CROPWAT 8.0}

CROPWAT is a crop water decision support tool for the estimation of evapotranspiration, yield prediction, and irrigation schedules, and estimates crop performance for irrigated and rain-fed conditions. Developed by Smith M in 1992 [51] by the Land and Water Development Division of Food and Agriculture Organization (FAO), CROPWAT has several evolutions and still meets the needs of modern farmers and researchers by providing features, such as the calculation of water requirements and the development of user-adjustable irrigation schedules, allowing the use of the CLIMWAT database tool by the FAO for climate data [52]. CROPWAT is an easy-to-use GUI-based tool where sample files and data are provided. In conjunction with the compatibility of interactions with CLIMWAT, the tool helps to reduce the multiple complexities of irrigation management. The tool is open source and easily downloadable from the FAO website [54].

\subsection{Aqua-Crop}

Aqua-Crop is another software package from the Land and Water Development Division of FAO with the ability to simulate canopy cover, ET, yield response, and biomass of the crop under different irrigation regimes [53]. Similar to the CROPWAT tool, AquaCrop can also be used to assist the management of irrigation for rain-fed and irrigated agriculture practices. The main feature of the tool is that it enables understanding of the response of the crop to changes in the environmental conditions, and the development of schemes for deficit irrigation conditions.

\subsection{SAPWAT}

Developed based on the paper by Allen, Periera, Raes and Smith, SAPWAT is an irrigation water requirement estimation tool based on the Penman-Monteith procedure for the calculation of ET [55]. It includes more than 50 years of weather data for approximately 3262 weather stations in South Africa. Features such as enterprise budget analysis distinguish this software from other existing tools used for irrigation management. SAPWAT seems to be inspired by the features of CROPWAT and has been developed as an alternative to CROPWAT. In addition to the three tools/software mentioned above, many other tools 
exist, most of which were specifically designed with geographical constraints or for use in a particular project.

\section{Observations and Discussions}

Many cloud platforms are available for the IoT, and each platform has its own specific features. Among the many available cloud platforms, ThingSpeak, Thingsworx, AWS IoT, IBM Watson, and Microsoft Azure are the eminent players.

Figure 5 showcases the most preferred cloud services utilized in the irrigation control and monitoring sector. The data in this section were observed from the papers referred to for this review. Open-source access, device management, security, implementation ease, data analytics and machine learning tools are the key factors that determine the use of cloud services for applications related to irrigation. ThingSpeak is highly utilized because it is highly instinctive and offers an open-source service for basic features. Remote monitoring is an important aspect for the implementation of IoT systems. The parameters that need to be monitored are the core factors that influence irrigation optimization. Figure 6 displays the parameters that are most considered for irrigation systems using IoT, where the temperature and humidity correspond to the air.

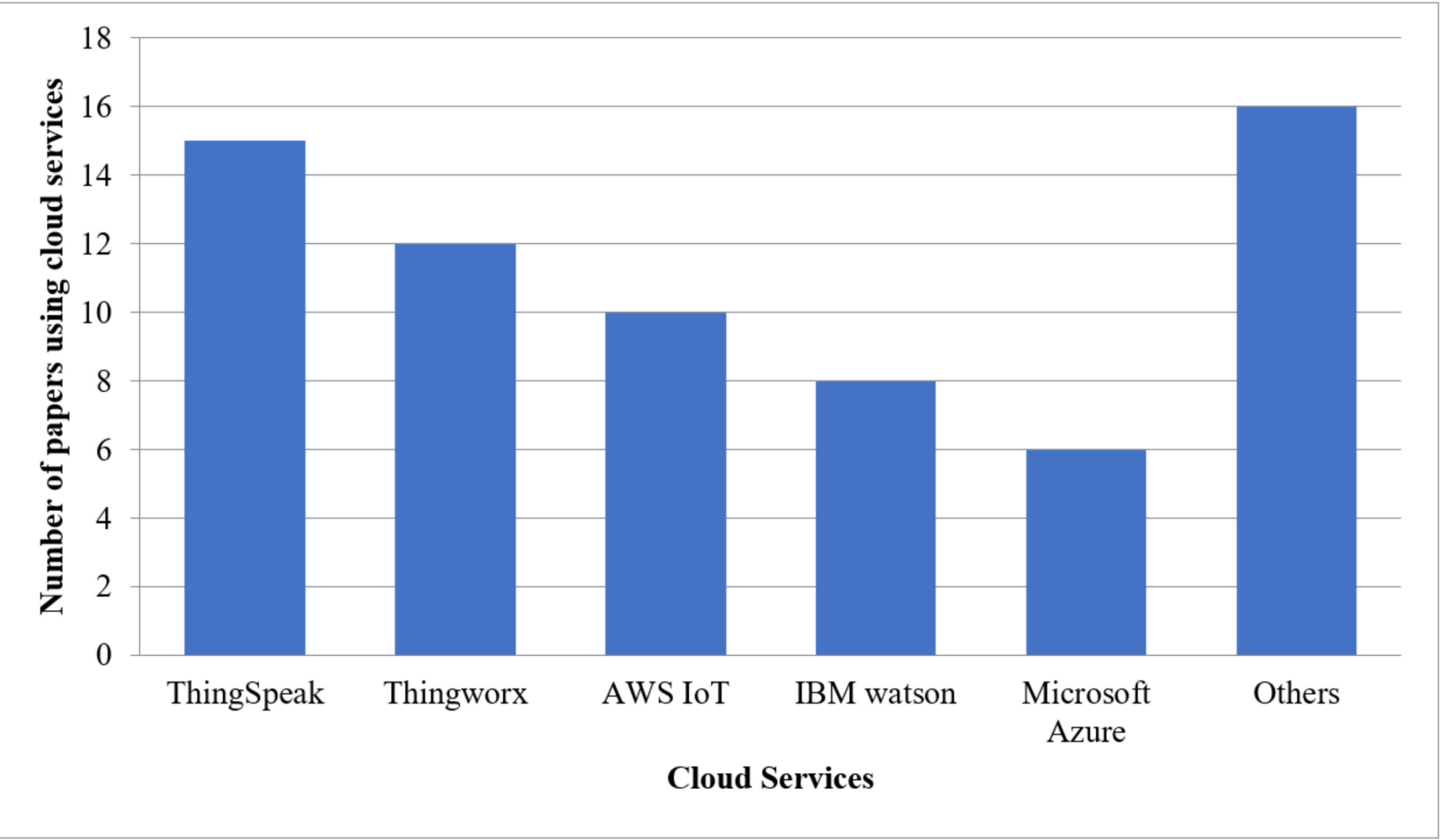

Figure 5. Key players in cloud service for irrigation.

Soil moisture, humidity, temperature, and rainfall are the key parameters considered for irrigation using the IoT. Other parameters, such as precipitation, wind speed, sunlight intensity, and wind direction, are also monitored in the implementations. Although evapotranspiration is also effectively utilized, it is derived using the other parameters; hence, it is not shown in Figure 6. The figure showcases only the parameters that are monitored in real time from the agricultural field. Other parameters, such as canopy and evapotranspiration, can be measured or calculated using the parameters that are monitored from the field.

Machine learning and ANN models for irrigation optimization have been in high demand in recent times, and some of the most utilized machine learning algorithms are compared with ANN models in Figure 7. Several ANN models, such as RNN, GRNN, and RBNN, are considered under the umbrella of ANN. The ANFIS, SVM, and GEP are the 
most preferred machine learning models. Machine learning models are more implemented and utilized for irrigation optimization than ANN models.

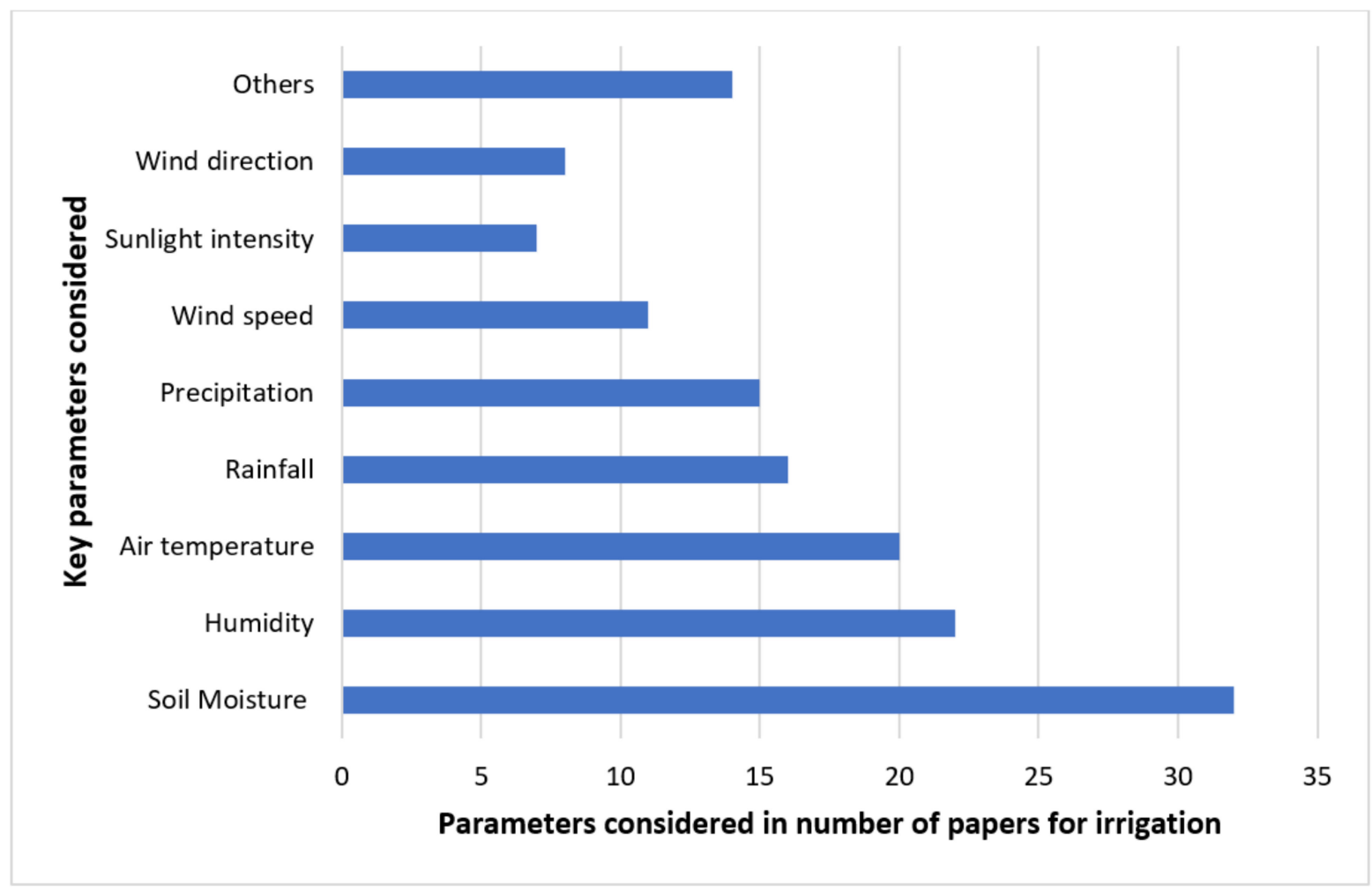

Figure 6. Key parameters considered for irrigation.

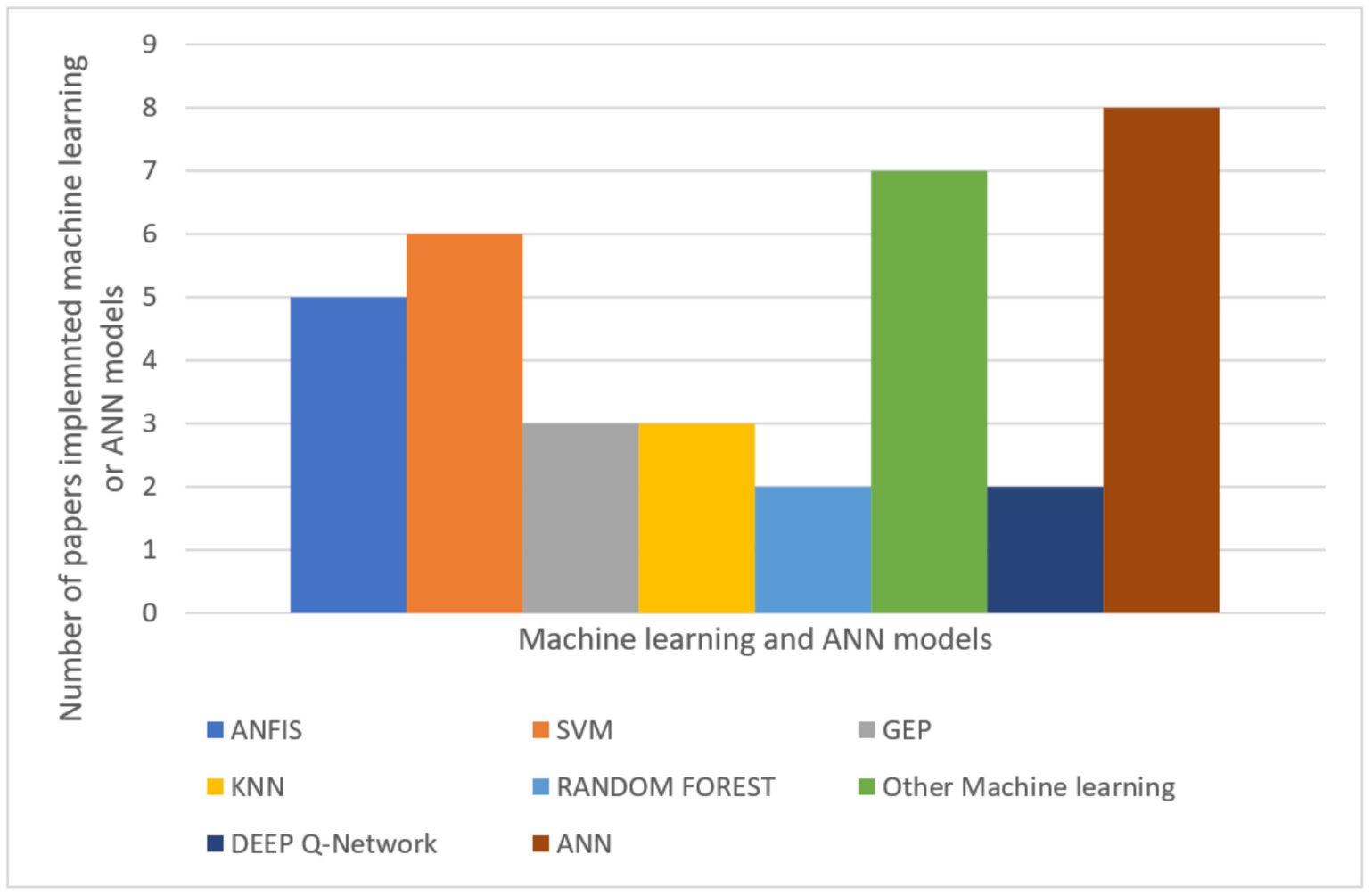

Figure 7. Most commonly used machine learning and ANN models. 


\section{Future Challenges}

The Internet of Things (IoT) presents several challenges researchers must address. In this paper, some vital challenges are discussed.

\subsection{Standard Protocols}

The varied ranges of sensors, controllers, and actuators utilized in the IoT lead to multiple challenges in the standardization of communication protocols, and varied devices or gadgets need to be integrated for IoT-based applications; hence, global standards are required so that adaptability and interoperability can be achieved. Difficulty in the Internet of Things is caused by the number of components involved, interoperability, communication protocols, and power sources. Devices use different communication protocols, such as MQTT, ZigBee, and TCP/IP. Although TCP/IP is the most utilized protocol, it leads to many complex issues. Therefore, many studies have been conducted to address the issue of complexity.

\subsection{Security in IoT-Based Systems}

When data are involved, security must be taken into utmost consideration, but due to the evolving nature of the IoT system and lack of standards, security is a decisive challenge that triggers ambiguous implementation. Security in communication protocols is not the only challenge, and security in routing is also very complex and still evolving. Security needs to be guaranteed for effective application utilization.

\subsection{Connectivity}

Providing Internet connectivity for agricultural fields may not be as easy as anticipated in developing and underdeveloped countries. Although connectivity seems to be feasible, the available bandwidth needs to be increased for many IoT applications. The Internet service providers need to expand their territory and range to reduce the key complexity of connectivity.

\subsection{Reliability of the Devices Involved}

The Internet of Things converges heterogeneous devices in one application, and the selection of durable devices is a critical factor for the reliability of the implementation of IoT applications. If one device fails, the entire application will fail.

\section{Conclusions}

Agriculture is an application-specific domain in which the implementation of the IoT and other emerging modern techniques and tools can provide new solutions for traditional problems. In this paper, several aspects of irrigation management using the IoT, and the available tools and approaches, are reviewed. The review can be summarized as follows:

- The IoT has facilitated the accumulation of information over a long duration, and since data are available, the implementation of machine learning and neural networks can result in identifying several insights that lead to the solution for a complex problem.

- The initial deployment cost for IoT enabled solution is an important concern for small scale farmers.

- Development of more agriculture specific sensors (soft or hard) needs to be undertaken. Hard sensors are traditional sensors that are available as physical hardware to sense the data, whereas soft sensors are a process/formula that converts the available various sensor data into intricate output data that require a very complex sensor to sense it. The development of soft sensors will reduce the cost and serve as an affordable alternative for expensive hard sensors.

- The service layer adds more modularity by acting as a middleware between the network and application layers. As IoT handles heterogeneous data and diverse services, the service layer adds more adaptability in developing applications. 
- IoT-based cloud platforms increase the effectiveness of the applications developed, but cost effectiveness, resource management, security, and configuration of IoT empowered devices need enhancement.

- Most of the test cases test only one crop cycle and are not applied to different crops.

- Labor and operation costs were not considered in most of the work.

- Machine learning and neural network approaches need to be provided with adequate data for effective analysis.

- The irrigation scheduling tools are effective but need to be provided with an ample quantity of data for useful results. Area-specific tools need to be developed.

- Irrigation management tools should be developed with direct access to sensor data from the field.

- A complete framework for the IoT in agriculture, starting from sensor deployment, analytics, and recommendation, has to be developed.

Author Contributions: Conceptualization, R.R. and I.H.; Data curation, B.P.K.; Formal analysis, R.R.; Funding acquisition, I.H., A.Y.E., A.H.A., A.A.A. and E.E.H.; Investigation, A.Y.E., A.H.A. and E.E.H.; Methodology, A.Y.E., A.H.A. and E.E.H.; Project administration, I.H.; Resources, I.H.; Software, I.H.; Supervision, A.Y.E., A.H.A., A.A.A. and E.E.H.; Validation, B.P.K., I.H. and A.Y.E.; Visualization, R.R.; Writing—original draft, V.R. and R.R.; Writing—review and editing, B.P.K., I.H., A.H.A., A.Y.E. and E.E.H. All authors have read and agreed to the published version of the manuscript.

Funding: This research was funded by the Taif University Researchers Supporting Project under grant number [TURSP-2020/252].

Institutional Review Board Statement: Not applicable.

Informed Consent Statement: Not applicable.

Data Availability Statement: Not applicable.

Acknowledgments: The authors are extremely thankful to the Taif University Researchers Supporting Project under grant number [TURSP-2020/252], Taif University, Saudi Arabia.

Conflicts of Interest: The authors declare no conflict of interest.

\section{References}

1. Clothier, B.E. Soil pores. In Encyclopedia of Soil Science; Springer: Dordrecht, The Netherlands, 2008; pp. $693-699$.

2. Ahmed, J.; van Bavel, C.H.M.; Hiler, E.A. Optimization of crop irrigation strategy under a stochastic weather regime: A simulation study. Water Resour. Res. 1976, 12, 1241-1247. [CrossRef]

3. Bhalage, P.; Jadia, B.; Sangale, S. Case Studies of Innovative Irrigation Management Techniques. Aquat. Procedia 2015, 4, 1197-1202. [CrossRef]

4. Foster, T.; Brozović, N.; Butler, A.P.; Neale, C.M.U.; Raes, D.; Steduto, P.; Fereres, E.; Hsiao, T.C. AquaCrop-OS: An open source version of FAO's crop water productivity model. Agric. Water Manag. 2017, 181, 18-22. [CrossRef]

5. Nikolaou, G.; Neocleous, D.; Christou, A.; Kitta, E.; Katsoulas, N. Implementing Sustainable Irrigation in Water-Scarce Regions under the Impact of Climate Change. Agronomy 2020, 10, 1120. [CrossRef]

6. Mendoza-Fernández, A.J.; Peña-Fernández, A.; Molina, L.; Aguilera, P.A. The Role of Technology in Greenhouse Agriculture: Towards a Sustainable Intensification in Campo de Dalías (Almería, Spain). Agronomy 2021, 11, 101. [CrossRef]

7. Moghazy, N.H.; Kaluarachchi, J.J. Sustainable Agriculture Development in the Western Desert of Egypt: A Case Study on Crop Production, Profit, and Uncertainty in the Siwa Region. Sustainability 2020, 12, 6568. [CrossRef]

8. Velasco-Muñoz, J.F.; Aznar-Sánchez, J.A.; Batlles-Delafuente, A.; Fidelibus, M.D. Rainwater Harvesting for Agricultural Irrigation: An Analysis of Global Research. Water 2019, 11, 1320. [CrossRef]

9. Gu, Z.; Qi, Z.; Burghate, R.; Yuan, S.; Jiao, X.; Xu, J. Irrigation Scheduling Approaches and Applications: A Review. J. Irrig. Drain. Eng. 2020, 146, 04020007. [CrossRef]

10. Hussain, I.; Khan, F.; Ahmad, I.; Khan, S.; Saeed, M. Power Loss Reduction via Distributed Generation System Injected in a Radial Feeder. Mehran Univ. Res. J. Eng. Technol. 2021, 40, 160-168. [CrossRef]

11. Holzapfel, E.A.; Mariño, M.A.; Chavez-Morales, J. Surface Irrigation Optimization Models. J. Irrig. Drain. Eng. 1986, 112, 1-19. [CrossRef]

12. Gao, X.; Lu, C.; Luan, Q.; Zhang, S.; Liu, J.; Han, D. Mapping Farmland-Soil Moisture at a Regional Scale Using a Distributed Hydrological Model: Case Study in the North China Plain. J. Irrig. Drain. Eng. 2016, 142, 04016029. [CrossRef] 
13. Karim, F.; Karim, F.; Frihida, A. Monitoring system using web of things in precision agriculture. Procedia Comput. Sci. 2017, 110, 402-409. [CrossRef]

14. Popović, T.; Latinović, N.; Pešić, A.; Zečević, Ž.; Krstajić, B.; Djukanović, S. Architecting an IoT-enabled platform for precision agriculture and ecological monitoring: A case study. Comput. Electron. Agric. 2017, 140, 255-265. [CrossRef]

15. Veerachamy, R.; Ramar, R. Agricultural Irrigation Recommendation and Alert (AIRA) system using optimization and machine learning in Hadoop for sustainable agriculture. Environ. Sci. Pollut. Res. 2021, 1-20. [CrossRef]

16. Yang, H.; Du, T.; Qiu, R.; Chen, J.; Wang, F.; Li, Y.; Wang, C.; Gao, L.; Kang, S. Improved water use efficiency and fruit quality of greenhouse crops under regulated deficit irrigation in northwest China. Agric. Water Manag. 2017, 179, 193-204. [CrossRef]

17. Zaman, S.; Hussain, I.; Singh, D. Fast Computation of Integrals with Fourier-Type Oscillator Involving Stationary Point. Mathematics 2019, 7, 1160. [CrossRef]

18. Talavera, J.M.; Tobon, L.; Gómez, J.A.; Culman, M.; Aranda, J.; Parra, D.T.; Quiroz, L.A.; Hoyos, A.; Garreta, L.E. Review of IoT applications in agro-industrial and environmental fields. Comput. Electron. Agric. 2017, 142, 283-297. [CrossRef]

19. Fazlali, A.; Shourian, M. A Demand Management Based Crop and Irrigation Planning Using the Simulation-Optimization Approach. Water Resour. Manag. 2017, 32, 67-81. [CrossRef]

20. Montesano, F.F.; van Iersel, M.; Boari, F.; Cantore, V.; D’Amato, G.; Parente, A. Sensor-based irrigation management of soilless basil using a new smart irrigation system: Effects of set-point on plant physiological responses and crop performance. Agric. Water Manag. 2018, 203, 20-29. [CrossRef]

21. Difallah, W.; Benahmed, K.; Draoui, B.; Bounaama, F. Linear Optimization Model for Efficient Use of Irrigation Water. Int. J. Agron. 2017, 2017, 5353648. [CrossRef]

22. Dang, T.; Pedroso, R.; Laux, P.; Kunstmann, H. Development of an integrated hydrological-irrigation optimization modeling system for a typical rice irrigation scheme in Central Vietnam. Agric. Water Manag. 2018, 208, 193-203. [CrossRef]

23. Zhang, H.; Xiong, Y.; Huang, G.; Xu, X.; Huang, Q. Effects of water stress on processing tomatoes yield, quality and water use efficiency with plastic mulched drip irrigation in sandy soil of the Hetao Irrigation District. Agric. Water Manag. 2017, 179, 205-214. [CrossRef]

24. Ghosh, S.; Sayyed, S.; Wani, K.; Mhatre, M.; Hingoliwala, H.A. Smart irrigation: A smart drip irrigation system using cloud, android and data mining. In Proceedings of the 2016 IEEE International Conference on Advances in Electronics, Communication and Computer Technology (ICAECCT), Pune, India, 2-3 December 2016; Institute of Electrical and Electronics Engineers (IEEE): Piscataway, NJ, USA, 2016; pp. 236-239.

25. Karimi, N.; Arabhosseini, A.; Karimi, M.; Kianmehr, M.H. Web-based monitoring system using Wireless Sensor Networks for traditional vineyards and grape drying buildings. Comput. Electron. Agric. 2018, 144, 269-283. [CrossRef]

26. Ullah, H.; Khan, M.; Hussain, I.; Ullah, I.; Uthansakul, P.; Khan, N. An Optimal Energy Management System for University Campus Using the Hybrid Firefly Lion Algorithm (FLA). Energies 2021, 14, 6028. [CrossRef]

27. Yu, S.; Lu, H. An integrated model of water resources optimization allocation based on projection pursuit model-Grey wolf optimization method in a transboundary river basin. J. Hydrol. 2018, 559, 156-165. [CrossRef]

28. Verma, R.D. Environmental Impacts of Irrigation Projects. J. Irrig. Drain. Eng. 1986, 112, 322-330. [CrossRef]

29. Jimenez-Carvajal, M.C.; García-Bañón, A.J.; Vera-Repullo, J.A.; Jimenez-Buendia, M.; Ruiz-Peñalver, L.; Martínez, J.M.M. Cloud-based monitoring system for lysimetric and agroclimatic data. Precis. Agric. 2017, 18, 1069-1084. [CrossRef]

30. Seelan, S.K.; Laguette, S.; Casady, G.M.; Seielstad, G.A. Remote sensing applications for precision agriculture: A learning community approach. Remote Sens. Environ. 2003, 88, 157-169. [CrossRef]

31. Liu, H.; Wang, X.; Zhang, X.; Zhang, L.; Li, Y.; Huang, G. Evaluation on the responses of maize (Zea mays L.) growth, yield and water use efficiency to drip irrigation water under mulch condition in the Hetao irrigation District of China. Agric. Water Manag. 2017, 179, 144-157. [CrossRef]

32. Barrett, C.E.; Zotarelli, L.; Paranhos, L.G.; Dittmar, P.; Fraisse, C.W.; VanSickle, J. Optimization of irrigation and N-fertilizer strategies for cabbage plasticulture system. Sci. Hortic. 2018, 234, 323-334. [CrossRef]

33. Fanuel, I.M.; Mushi, A.; Kajunguri, D. Irrigation water allocation optimization using multi-objective evolutionary algorithm (MOEA)-A review. Int. J. Simul. Multidiscip. Des. Optim. 2018, 9, A3. [CrossRef]

34. Sawant, S.; Durbha, S.S.; Jagarlapudi, A. Interoperable agro-meteorological observation and analysis platform for precision agriculture: A case study in citrus crop water requirement estimation. Comput. Electron. Agric. 2017, 138, 175-187. [CrossRef]

35. Hussain, I.; Ullah, M.; Ullah, I.; Bibi, A.; Naeem, M.; Singh, M.; Singh, D. Optimizing Energy Consumption in the Home Energy Management System via a Bio-Inspired Dragonfly Algorithm and the Genetic Algorithm. Electronics 2020, 9, 406. [CrossRef]

36. Severino, G.; D'Urso, G.; Scarfato, M.; Toraldo, G. The IoT as a tool to combine the scheduling of the irrigation with the geostatistics of the soils. Future Gener. Comput. Syst. 2018, 82, 268-273. [CrossRef]

37. Akbari, M.; Gheysari, M.; Mostafazadeh-Fard, B.; Shayannejad, M. Surface irrigation simulation-optimization model based on meta-heuristic algorithms. Agric. Water Manag. 2018, 201, 46-57. [CrossRef]

38. Hu, F.; Shao, L. Design of remote irrigation system in farmland based on the cloud platform. In Proceedings of the 201729 th Chinese Control and Decision Conference (CCDC), Chongqing, China, 28-30 May 2017; IEEE: Piscataway, NJ, USA, 2017; pp. 1125-1129.

39. Ullah, I.; Hussain, I.; Singh, M. Exploiting Grasshopper and Cuckoo Search Bio-Inspired Optimization Algorithms for Industrial Energy Management System: Smart Industries. Electronics 2020, 9, 105. [CrossRef] 
40. Zhang, X.; Zhang, J.; Li, L.; Zhang, Y.; Yang, G. Monitoring Citrus Soil Moisture and Nutrients Using an IoT Based System. Sensors 2017, 17, 447. [CrossRef]

41. Tan, L. Cloud-based Decision Support and Automation for Precision Agriculture in Orchards. IFAC-PapersOnLine 2016, 49, 330-335. [CrossRef]

42. Liao, M.S.; Chen, S.F.; Chou, C.Y.; Chen, H.Y.; Yeh, S.H.; Chang, Y.C.; Jiang, J.A. On precisely relating the growth of Phalaenopsis leaves to greenhouse environmental factors by using an IoT-based monitoring system. Comput. Electron. Agric. 2017, 136, 125-139. [CrossRef]

43. Sethi, P.; Sarangi, S.R. Internet of Things: Architectures, Protocols, and Applications. J. Electr. Comput. Eng. 2017, $2017,9324035$. [CrossRef]

44. Hussain, I.; Samara, G.; Ullah, I.; Khan, N. Encryption for End-User Privacy: A Cyber-Secure Smart Energy Management System. In Proceedings of the 2021 22nd International Arab Conference on Information Technology (ACIT), Muscat, Oamn, 21-23 December 2021; IEEE: Piscataway, NJ, USA, 2021; pp. 1-6. [CrossRef]

45. Miikkulainen, R.; Liang, J.; Meyerson, E.; Rawal, A.; Fink, D.; Francon, O.; Raju, B.; Shahrzad, H.; Navruzyan, A.; Duffy, N.; et al. Evolving Deep Neural Networks. In Artificial Intelligence in the Age of Neural Networks and Brain Computing; Academic Press: Cambridge, MA, USA, 2019; pp. 293-312.

46. Jing, W.; Yaseen, Z.M.; Shahid, S.; Saggi, M.K.; Tao, H.; Kisi, O.; Salih, S.Q.; Al-Ansari, N.; Chau, K.-W. Implementation of evolutionary computing models for reference evapotranspiration modeling: Short review, assessment and possible future research directions. Eng. Appl. Comput. Fluid Mech. 2019, 13, 811-823. [CrossRef]

47. Pour, O.M.R.; Piri, J.; Kisi, O. Comparison of SVM, ANFIS and GEP in modeling monthly potential evapotranspiration in an arid region (Case study: Sistan and Baluchestan Province, Iran). Water Supply 2018, 19, 392-403. [CrossRef]

48. Feng, Y.; Cui, N.; Gong, D.; Zhang, Q.; Zhao, L. Evaluation of random forests and generalized regression neural networks for daily reference evapotranspiration modelling. Agric. Water Manag. 2017, 193, 163-173. [CrossRef]

49. Yamaç, S.S.; Todorovic, M. Estimation of daily potato crop evapotranspiration using three different machine learning algorithms and four scenarios of available meteorological data. Agric. Water Manag. 2020, 228, 105875. [CrossRef]

50. Sanikhani, H.; Kisi, O.; Maroufpoor, E.; Yaseen, Z.M. Temperature-based modeling of reference evapotranspiration using several artificial intelligence models: Application of different modeling scenarios. Arch. Meteorol. Geophys. Bioclimatol. Ser. B 2019, 135, 449-462. [CrossRef]

51. Smith, M. CROPWAT: A Computer Program for Irrigation Planning and Management; No 46; FAO: Rome, Italy, $1992 ;$ p. 126.

52. Pushpalatha, R.; Amma, S.S.; George, J.; Rajan, S.; Gangadharan, B. Development of optimal irrigation schedules and crop water production function for cassava: Study over three major growing areas in India. Irrig. Sci. 2020, 38, 251-261. [CrossRef]

53. Vanuytrecht, E.; Raes, D.; Steduto, P.; Hsiao, T.C.; Fereres, E.; Heng, L.K.; Garcia-Vila, M.; Moreno, P.M. AquaCrop: FAO's crop water productivity and yield response model. Environ. Model. Softw. 2014, 62, 351-360. [CrossRef]

54. FAO. CropWat. Available online: http://www.fao.org/land-water/databases-and-software/cropwat/en/ (accessed on 10 October 2021).

55. Allen, R.G.; Pereira, L.S.; Raes, D.; Smith, M. FAO irrigation and drainage, crop evapotranspiration. Guidel. Comput. Crop Water Requir. 1998, 56, 1-156.

56. Tousi, E.G.; Duan, J.G.; Gundy, P.M.; Bright, K.R.; Gerba, C.P. Evaluation of E. coli in sediment for assessing irrigation water quality using machine learning. Sci. Total Environ. 2021, 799, 149286. [CrossRef]

57. Møller, A.; Mulder, V.; Heuvelink, G.; Jacobsen, N.; Greve, M. Can We Use Machine Learning for Agricultural Land Suitability Assessment? Agronomy 2021, 11, 703. [CrossRef]

58. Paudel, D.; Boogaard, H.; de Wit, A.; Janssen, S.; Osinga, S.; Pylianidis, C.; Athanasiadis, I.N. Machine learning for large-scale crop yield forecasting. Agric. Syst. 2021, 187, 103016. [CrossRef]

59. Agricultural Economics. Precision Agriculture Usage and Big Agriculture Data. Available online: https://agecon.unl.edu/ cornhusker-economics/2015/precision-agriculture-usage-and-big-agriculture-data (accessed on 31 December 2021).

60. Corps, P. Irrigation Reference Manual; Information Collection \& Exchange: Washington, DC, USA, 1990.

61. Ullah, I.; Hussain, I.; Uthansakul, P.; Riaz, M.; Khan, M.N.; Lloret, J. Exploiting Multi-Verse Optimization and Sine-Cosine Algorithms for Energy Management in Smart Cities. Appl. Sci. 2020, 10, 2095. [CrossRef]

62. Yousif, J.H.; Abdalgader, K. Experimental and Mathematical Models for Real-Time Monitoring and Auto Watering Using IoT Architecture. Computers 2022, 11, 7. [CrossRef]

63. Alibabaei, K.; Gaspar, P.D.; Assunção, E.; Alirezazadeh, S.; Lima, T.M. Irrigation optimization with a deep reinforcement learning model: Case study on a site in Portugal. Agric. Water Manag. 2022, 263, 107480. [CrossRef]

64. Abioye, E.A.; Hensel, O.; Esau, T.J.; Elijah, O.; Abidin, M.S.Z.; Ayobami, A.S.; Yerima, O.; Nasirahmadi, A. Precision Irrigation Management Using Machine Learning and Digital Farming Solutions. AgriEngineering 2022, 4, 70-103. [CrossRef]

65. Sami, M.; Khan, S.Q.; Khurram, M.; Farooq, M.U.; Anjum, R.; Aziz, S.; Qureshi, R.; Sadak, F. A Deep Learning-Based Sensor Modeling for Smart Irrigation System. Agronomy 2022, 12, 212. [CrossRef]

66. Cordeiro, M.; Markert, C.; Araújo, S.S.; Campos, N.G.; Gondim, R.S.; da Silva, T.L.C.; da Rocha, A.R. Towards Smart Farming: Fog-enabled intelligent irrigation system using deep neural networks. Futur. Gener. Comput. Syst. 2021, 129, 115-124. [CrossRef]

67. Zaman, S.; Khan, L.U.; Hussain, I.; Mihet-Popa, L. Fast Computation of Highly Oscillatory ODE Problems: Applications in High-Frequency Communication Circuits. Symmetry 2022, 14, 115. [CrossRef] 
68. Verma, A.; Bodade, R. Low-Cost IoT Framework for Indian Agriculture Sector: A Compressive Review to Meet Future Expectation. In Proceedings of the Second International Conference on Computer Networks and Communication Technologies; Springer Science and Business Media LLC: Berlin/Heidelberg, Germany, 2022; pp. 241-258.

69. Jiménez, A.F.; Cárdenas, P.F.; Jiménez, F. Intelligent IoT-multiagent precision irrigation approach for improving water use efficiency in irrigation systems at farm and district scales. Comput. Electron. Agric. 2022, 192, 106635. [CrossRef]

70. Prabakaran, S.; Ramar, R.; Hussain, I.; Kavin, B.P.; Alshamrani, S.S.; AlGhamdi, A.S.; Alshehri, A. Predicting Attack Pattern via Machine Learning by Exploiting Stateful Firewall as Virtual Network Function in an SDN Network. Sensors 2022, 22, 709. [CrossRef]

71. Mezouari, A.E.; Fazziki, A.E.; Sadgal, M. Towards Smart Farming through Machine Learning-Based Automatic Irrigation Planning. In Smart Sensor Networks; Springer: Cham, Switzerland, 2022; pp. 179-206.

72. Ahmad, F.; Ahmad, A.; Hussain, I.; Uthansakul, P.; Khan, S. Cooperation Based Proactive Caching in Multi-Tier Cellular Networks. Appl. Sci. 2020, 10, 6145. [CrossRef]

73. Abimbola, O.P.; Franz, T.E.; Rudnick, D.; Heeren, D.; Yang, H.; Wolf, A.; Katimbo, A.; Nakabuye, H.N.; Amori, A. Improving crop modeling to better simulate maize yield variability under different irrigation managements. Agric. Water Manag. 2021, 262, 107429. [CrossRef]

74. Wolff, W.; Francisco, J.P.; Flumignan, D.L.; Marin, F.R.; Folegatti, M.V. Optimized algorithm for evapotranspiration retrieval via remote sensing. Agric. Water Manag. 2021, 262, 107390. [CrossRef] 